\title{
Update on pathogenesis and diagnosis flow of normoalbuminuric diabetes with renal insufficiency
}

Le Deng ${ }^{\dagger}$, Wenjie $\mathrm{Li}^{\dagger}$ and Gaosi $\mathrm{Xu}^{*}$

\begin{abstract}
In recent decades, the prevalence of diabetic kidney disease has remained stable and appears to be a wide heterogeneity. Normoalbuminuric diabetes with renal insufficiency, which is characterized by a decline in the glomerular filtration rate in the absence of albuminuria, has been identified as an albuminuria-independent phenotype of diabetic kidney disease. Epidemiological data demonstrate that normoalbuminuric phenotype is prevalent. Compared to albuminuric phenotype, normoalbuminuric phenotype has distinct clinical characteristics and a wide heterogeneity of pathological features. Currently, the pathogenesis of normoalbuminuric phenotype remains unclear. Additionally, the flow of diagnosing normoalbuminuric phenotype is not perfect. In this article, we review the latest studies addressing the epidemiology, clinical characteristics, and pathology of normoalbuminuric phenotype. Based on the studies of clinical features and renal histopathologic changes, we attempt to propose an underlying pathogenesis model and a flow chart for diagnosing normoalbuminuric phenotype.
\end{abstract}

Keywords: Diabetes Mellitus, Normoalbuminuric, Phenotype, Glomerular Filtration Rate, Renal Insufficiency

\section{Introduction}

Over the years, albuminuria has been regarded as a pivotal indicator of diabetic kidney disease (DKD) and invariably precedes estimated glomerular filtration rate (eGFR) loss. However, this classical view has been challenged by evidence that a considerable proportion of patients with diabetes have renal insufficiency in the absence of albuminuria, referred to normoalbuminuric diabetic kidney disease $[1,2]$ or nonalbuminuric diabetic nephropathy $[1,3]$ or diabetic kidney disease without albuminuria [4], or nonalbuminuric renal insufficiency in type 2 diabetes [5], defined as eGFR $<60 \mathrm{~mL} / \mathrm{min}$ per 1.73 $\mathrm{m}^{2}$ and in the absence of albuminuria (urinary albumin

\footnotetext{
*Correspondence: gaosixu@163.com

${ }^{\dagger}$ Le Deng and Wenjie Li have contributed equally to this work and share first authorship

Department of Nephrology, The Second Affiliated Hospital of Nanchang University, No. 1, Minde Road, Donghu District, Nanchang, Jiangxi 330006, People's Republic of China
}

excretion rate $(\mathrm{UAER})<30 \mathrm{mg} / 24 \mathrm{~h}$ or urinary albumin creatinine ratio $(\mathrm{UACR})<30 \mathrm{mg} / \mathrm{g}$ ), has been identified as albuminuria-independent phenotype of DKD [6, 7]. The Italian Diabetes Society and Italian Society of Nephrology also well described the nonalbuminuric renal impairment phenotype in a joint position statement on the natural history of diabetes mellitus in 2020 [8].

The combination of renal insufficiency and normoalbuminuria in diabetes was first highlighted by Lane et al. in 1992 [9], and has been confirmed for decades. The prevalence of the normoalbuminuric diabetes with renal insufficiency (NADRI) increased and has become a prevailing phenotype of DKD at present [10]. Even though these patients carry a lower risk for chronic kidney disease (CKD) progression, end-stage renal disease, or cardiovascular disease or all-cause mortality compared to those with albuminuric diabetes with renal insufficiency (ADRI) [7, 11-19], it significantly contributes to the burden of advanced CKD or end-stage renal disease 
morbidity $[6,13,20]$. Moreover, mortality rates generally increased in these patients [10].

Currently, the natural course and potential pathogenesis of NADRI are still elusive. In this article, we review the latest studies addressing the epidemiology, clinical characteristics, and pathology of NADRI. Based on the studies of clinical features and renal histopathologic changes, we attempt to propose an underlying pathogenesis model and a flow chart for diagnosing NADRI.

\section{Epidemiology}

Two early studies reported that renal insufficiency may occur in both type 1 diabetes mellitus (T1DM) and type 2 diabetes mellitus (T2DM) with normoalbuminuria [9, 21 ], and these observations have been confirmed in subsequent studies.

In T2DM, the prevalence of NADRI ranges from 14 to $57 \%$ in cross-sectional studies, with differences among surveys depending on the geographic area and the calculation formula of eGFR $[5,13,14,21-36]$. A higher incidence of NADRI (more than 60\%) was observed in recent years [37-41]. Similar high prevalence was noted in multicenter multinational interventional researches, in which values were affected by different inclusion criteria, nevertheless [42-45]. Different from T2DM, the prevalence variation of NADRI in T1DM is significant, which ranges from 2 to $58 \%[9,15,38,46-48]$. A recent study indicated that the proportion of NADRI was remarkably high (58.6\%) [49].

These data are in line with the increasing prevalence of declined eGFR and the decreasing incidence of albuminuria observed in diabetes $[50,51]$. The increasing prevalence of NADRI may be partly due to the wide application of renin-angiotensin-aldosterone system (RAAS) inhibitors, advances in the treatment of antihyperglycemic, antihypertensive and hypolipidemic, and smoking cessation [19, 24, 52-54].

\section{Clinical characteristics}

The reported clinical features of NADRI include a higher proportion of females $[7,15,16,36,37,47]$, more likely to be older $[15,16,47]$ and nonsmokers $[7,15,16,36,37$, 47]; a shorter diabetes duration [36, 55, 56]; lower levels of systolic blood pressure [7, 13, 15, 16, 36, 37, 47, 55, 56], diastolic blood pressure [13, 15, 16, 47, 55], hemoglobin A1c (HbA1c) [7, 15, 36, 37, 47], triglycerides[15, 36, 37, 47], total cholesterol [13, 15, 47, 55], and low-density lipoprotein cholesterol [13, 15, 47]; higher levels of highdensity lipoprotein cholesterol [15, 18, 36, 47]; and lower prevalence of diabetic retinopathy $[7,15,18,37,55,56]$, neuropathy [55], and cardiovascular disease [7, 16, 37], as compared to patients with ADRI (Table 1).
Compared to patients with micro-ADRI and/or macroADRI, the clinical features of NADRI include a higher proportion of females $[5,18,57]$, more likely to be older $[5,20]$ and nonsmokers $[18,23,58]$, a shorter diabetes duration [57]; lower levels of systolic blood pressure [20], diastolic blood pressure [20], HbA1c [20, 23, 57], and triglycerides [20]; higher levels of high-density lipoprotein cholesterol[20]; and lower prevalence of hypertension [57], diabetic retinopathy [23, 57], and cardiovascular disease [23] (Table 2).

In addition, compared to patients with normoalbuminuric preserved renal function (eGFR $>60 \mathrm{~mL} /$ $\mathrm{min} / 1.73 \mathrm{~m}^{2}$ ), individuals with NADRI are older $[16,28$, $59]$, more frequently females $[16,28,59]$ and nonsmokers $[16,28]$, and have a higher prevalence of hypertension $[28,60]$ and hyperlipidemia (including triglycerides, total cholesterol, or low-density lipoprotein cholesterol) [28, 59] and metabolic syndrome [59] and cardiovascular disease $[24,28]$.

\section{Pathology}

A retrospective study found albuminuria or/and low eGFR was absent in nearly $20 \%$ [20 of 106] of individuals throughout life showed histopathologic changes characteristic of DKD. Moreover, structural changes were greatly variable, including almost all histopathologic classification of DKD[61].

\section{Glomerular lesions}

A Cohen diabetic rat animal model exhibited extracellular matrix accumulation, mesangial expansion, glomerular basement membrane width increasement, and type IV collagen increasement in the glomeruli, resulting in typical diabetic glomerulosclerosis morphological changes [62]. As early as 1992, Lane et al. reported that the patients with low creatinine clearance rate/normal urinary albumin excretion had more mesangial expansion and glomerular sclerosis compared with patients with normal creatinine clearance rate/normal urinary albumin excretion [9]. Subsequent studies have also shown that patients with NADRI had more advanced glomerular injury compared to individuals with preserved renal function $[56,63]$.

On the other hand, a significant difference between individuals with NADRI and ADRI was observed, the former had fewer typical glomerular features related with diabetic glomerulopathy or less serious diabetic changes $[64,65]$. A previous study found that mesangial area progressively increased from normal control individuals to patients with diabetes and normoalbuminuria, microalbuminuria, and macroalbuminuria, and 3 in 8 patients with NADRI showed typical glomerular changes, whereas the prevalence in patients with microalbuminuria and 


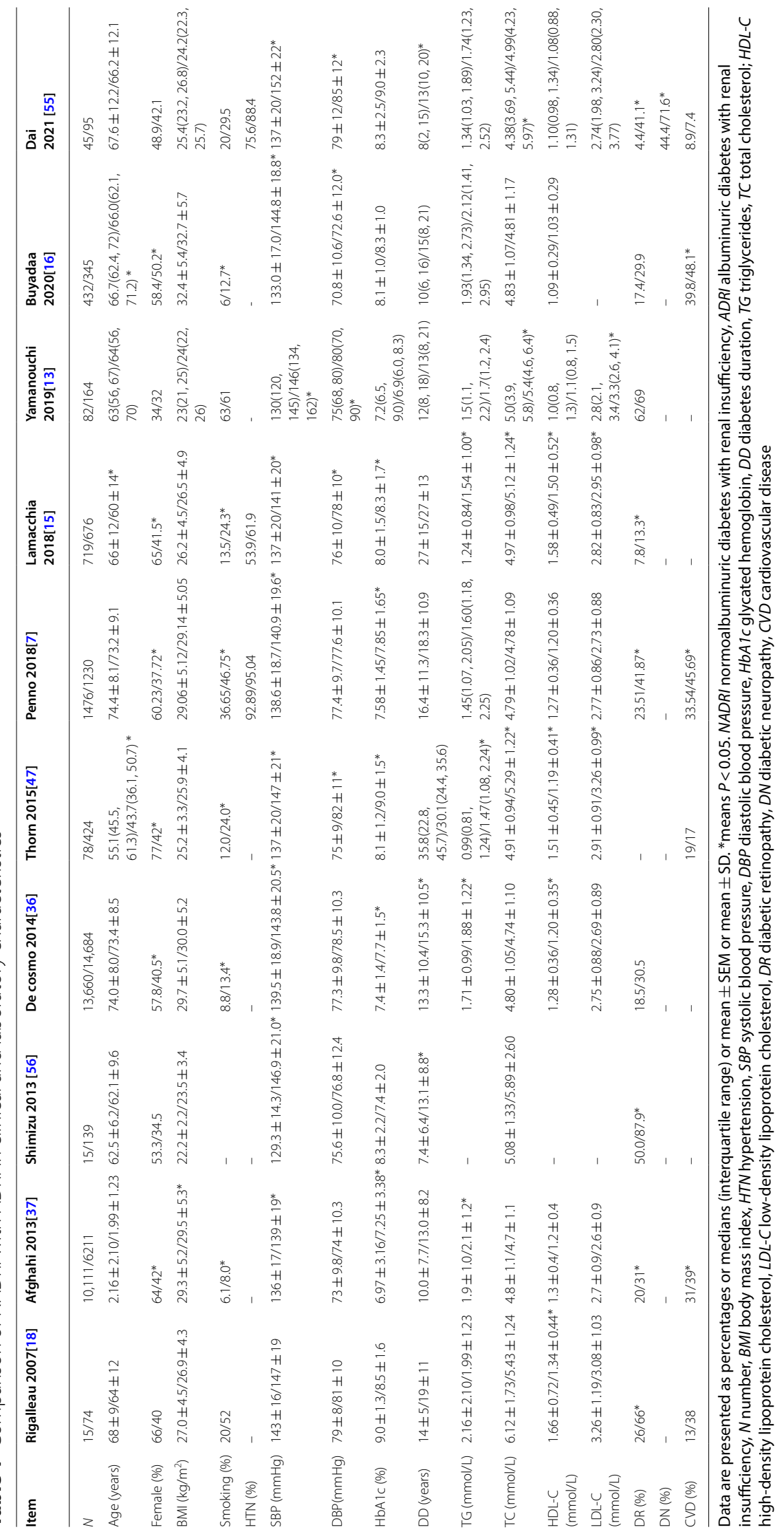




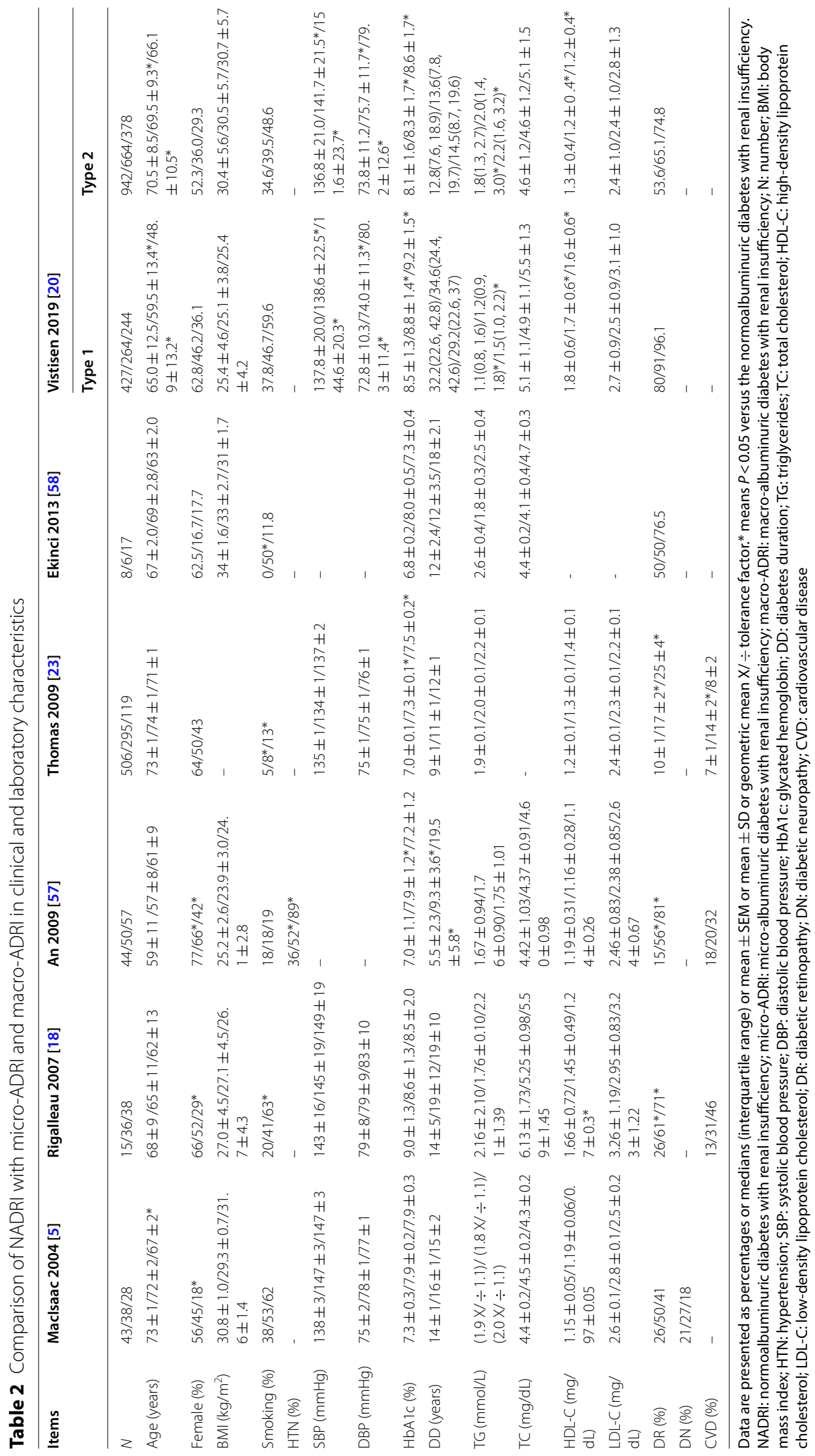


macroalbuminuria was 5 in 6 and 17 in 17, respectively [58]. Advanced DKD (class III, nodular lesions without global sclerosis in $>50 \%$ of the glomeruli or more) was noted in only $27 \%$ of patients with NADRI; nevertheless, it was observed in $62 \%$ of patients with ADRI [13].

\section{Tubulointerstitial lesions}

Compared to those with normoalbuminuria and preserved eGFR, tubulointerstitial injury of patients with NADRI was more advanced [56, 65]. Similarly, different from typical glomerular changes mostly in individuals with ADRI, predominant interstitial fibrosis and/or tubular atrophy (IFTA) were more frequent findings in patients with NADRI. In the study by Ekinci et al. [58], 3 out of $8(37.5 \%)$ patients with NADRI had disproportionately severe interstitial, tubular lesions; however, only 1 out of $23(4.3 \%)$ individuals with ADRI had these changes.

In addition, in the researches for new biomarkers that identify the risk of reducing glomerular filtration rate (GFR) independent of albuminuria in diabetes, levels of kidney injury molecule-1 (KIM-1), neutrophil gelatinaseassociated lipocalin (NGAL), and retinol-binding protein (RBP), tubular damage biomarkers were increased in NADRI, significantly correlated with eGFR and may serve as noninvasive biomarkers of NADRI $[66,67]$, to some extent, which support the tubular injury in NADRI.

\section{Vascular lesions}

As compared to those with normoalbuminuria and preserved eGFR, vascular lesions in patients with NADRI were more advanced. Likewise, compared to patients with ADRI, vascular lesions of individuals with NADRI were similar or more advanced in contrast to glomerular lesions [56].

Previous clinical observations found, compared to those with or without albuminuria and preserved eGFR, that patients with NADRI are related to a higher risk of major cardiovascular events or cardiovascular morbidity and death [16, 17, 42, 47, 55, 68, 69], and there is a positive association of the prevalence of NADRI with metabolic syndrome and other macrovascular complications $[24,27,59]$. In addition, NADRI shows no or weak relationship with $\mathrm{HbA1c}$ and the other major microvascular complications of diabetes (diabetic retinopathy, neuropathy), e.g., up to approximately $30-50 \%$ of individuals with decreased eGFR, show neither albuminuria nor retinopathy $[22,24,28$, $36,37,57]$. Similarly, death in the NADRI is not related to the classic 'microvascular' features or factors, such as diabetic retinopathy and glycemic exposure (diabetes duration, HbA1c) [7]. These data indicate that NADRI exhibit distinct clinical characteristics, suggesting predominance of macroangiopathy rather than microangiopathy as underlying renal pathology $[5,24,65]$.

Diabetic patients with an eGFR $<60 \mathrm{~mL} / \mathrm{min}$ per 1.73 $\mathrm{m}^{2}$ have a higher renal artery resistance index and a greater degree of intrarenal vascular disease (measured by the intrarenal resistance index) than patients with preserved eGFR, and this difference is independent of UAER[70]. Further studies indicated that patients with NADRI had more serious carotid atherosclerosis [55]

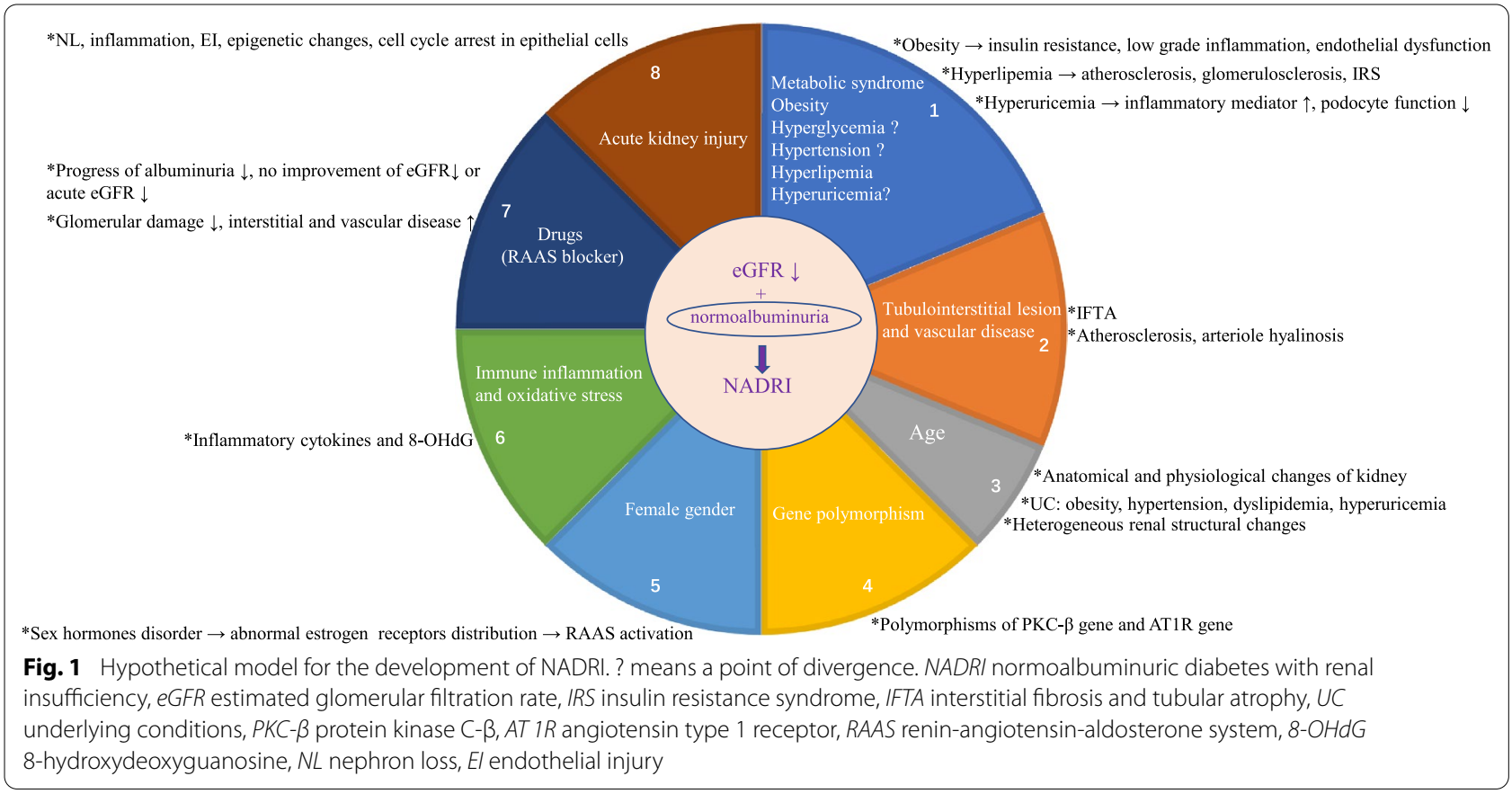


and more advanced renal arteriosclerosis than diabetic patients with normoalbuminuria and preserved eGFR [56]. Moreover, in the study by Ekinci et al., in the individuals with NADRI, 7 out of 8 had varying degrees of renal arteriosclerosis [58]. Besides arteriosclerosis, NADRI had more advanced arteriolar hyalinosis compared to patients with normoalbuminuria and preserved eGFR [56].

\section{Pathogenesis}

Currently, the pathogenesis of NADRI remains to be fully elucidated. The proposed pathogenic mechanisms that underlie NADRI are multifactorial, complex and may involve age-associated renal senescence, hypertension, dyslipidemia, obesity, renal hypertensive and interstitial fibrosis, vascular disease, arteriosclerosis, cholesterol microemboli, lipid toxicity, inflammation, and masking of albuminuria by RAAS inhibitors $[4,5,22,28,58,70-$ 72 ]. Based on the clinical research of identified clinical and pathological characteristics, we attempt to propose a hypothetical model for the development of NADRI (Fig. 1).

\section{Metabolic syndrome}

The presence of low eGFR in diabetic patients with normoalbuminuria is associated with the presence of metabolic syndrome [59]. Risk factors that may trigger a progressive decrease of GFR in normoalbuminuria include obesity, hypertension, and high serum triglycerides levels in diabetes [73], and these mechanisms often play a role in nephrosclerosis [74].

\section{Obesity}

In T2DM, obesity from the overweight category (body mass index $25-29.9 \mathrm{~kg} / \mathrm{m}^{2}$ ) to severe obesity (body mass index $>35 \mathrm{~kg} / \mathrm{m}^{2}$ ) was related to reduced renal function in the absence of albuminuria [75]. Increased waist circumference was independent risk factor for renal insufficiency[29].

Adverse effects of obesity may include insulin resistance, low-grade inflammation, and endothelial dysfunction, and these pathways have been reported as potential mechanisms for the development of renal insufficiency [76-78].

\section{Hyperglycemia}

The Atherosclerosis Risk in Communities Study, which enrolled 1871 patients with diabetes, showed a similar decline in the incidence of decreased eGFR $<60 \mathrm{~mL} /$ $\mathrm{min} / 1.73 \mathrm{~m}^{2}$ for every $1 \%$ reduction in $\mathrm{HbA} 1 \mathrm{c}$, regardless of preexisting albuminuria [79]. Poor glycemic control is an independent predictor of progression to end-stage renal disease in T1DM patients with normoalbuminuria [80]. These data indicated that hyperglycemia may be associated with eGFR decline in NADRI.

However, HbA1c is an independent risk factor for albuminuria, but not for GFR impairment [24, 29, 75]; thus, NADRI is probably less related to hyperglycemia. Some researches propose that diabetes contributes to the NADRI development via pathways which may be partially separated from hyperglycemia. Amy et al's study showed that in the diabetic patients with low and even 'normal' HbA1c levels, the prevalence of NADRI is still higher than that in the nondiabetic individuals [2]. NADRI is more common in individuals with good glycemic control [55]. Moreover, both HbA1c levels and the prevalence of microvascular complications are lower in individuals with NADRI $[5,18,22,23,28]$. These data indicate that potential pathogenic mechanisms of NADRI may be at least partially independent of hyperglycemia [2].

\section{Hypertension}

Among normoalbuminuric diabetes, higher prevalence of hypertension is observed in patients with low eGFR than in those with preserved eGFR. Blood pressure perturbations may contribute to reduce kidney function independently of albuminuria [58]. Each $10 \mathrm{mmHg}$ increase in mean systolic blood pressure was related to a $15 \%$ increase in the hazard ratio for renal insufficiency defined as eGFR $<60 \mathrm{~mL} / \mathrm{min} / 1.73 \mathrm{~m}^{2}$ or doubling blood creatinine level[29]. These studies provided clinical evidence that hypertension may contribute to renal insufficiency and play a role in the development of NADRI.

However, in the study by Mottl et al. [2], the lower prevalence of NADRI in individuals with poor control of hypertension suggested hypertension was less likely to be a key factor of NADRI. In addition, there is a well-documented relationship between hypertension and albuminuria in diabetes [81]. On the other hand, it cannot exclude the threshold effect of blood pressure on albuminuria and/or on renal damage mediated by hypertension [2]. Therefore, underlying pathogenesis of NADRI may be at least partially independent of hypertension.

\section{Hyperlipidemia}

Low eGFR in normoalbuminuric diabetes was related to high levels of triglycerides [59]. Hyperlipidemia (high triglycerides, high total cholesterol, or low high-density lipoprotein cholesterol) is the independently factor related to renal impairment $[28,75,82]$. A recent study has reported that increased lipid abnormalities play a certain role in the occurrence and development of NADRI [71]. Further studies indicate that insulin resistance syndrome may underlie or mediate the relationship 
between lipids and renal function loss [82] and hypercholesterolemia may cause kidney damage by atherosclerosis and glomerulosclerosis [83].

In addition, treatment of dyslipidemia may reduce the incidence of early renal disease [82], and the relationship between cholesterol-lowering treatment and renal dysfunction progression in diabetes was independent of UAER [84].

\section{Hyperuricemia}

Previous studies have reported an independent association between serum uric acid levels and eGFR decline in diabetes [85-89]. A large study of 1052 cases showed that serum uric acid may play an important role in the reduction of eGFR in elderly diabetic individuals with normoalbuminuria [90]. Serum uric acid-promoting eGFR loss may be due to proinflammatory mechanisms [91] and led to renal fibrosis, glomerulosclerosis, and tubular lesions with inflammatory mediators elevation and decreased podocyte function [92]. However, Hanai et al. showed that high serum uric acid level was a prognostic factor for renal function decrease only in individuals with preserved renal function [93].

Currently, a randomized, double-blind, placebo-controlled, multicenter clinical trial that has enrolled 530 patients with T1DM, the Preventing Early Renal Loss in Diabetes Study, will explore whether the effect of lowering serum uric acid with allopurinol should be able to slow GFR loss on mild to moderate DKD with or without albuminuria. In this study, nearly one-fifth of normoalbuminuric patients with declining kidney function were enrolled, and the results of the clinical trial are worth looking forward to [94].

\section{Tubulointerstitial lesion and vascular disease}

Clinical pathological studies have demonstrated that predominant tubulointerstitial and vascular lesions are more frequently observed in NADRI. In diabetes, tubulointerstitial injury (e.g., interstitial fibrosis, interstitial fibrosis and tubular atrophy) $[13,56,61,95]$ and vascular lesions (e.g., intrarenal vascular disease) are the factors associated with low eGFR, independently of albuminuria $[56,70]$. It is speculated that declining of eGFR may be partly related to tubulointerstitial and vascular lesions in NADRI.

The markers of renal tubular injury, such as NGAL, RBP, and KIM-1, have been found significantly increased in NADRI and weakly but significantly correlated with eGFR, suggesting that renal tubular interstitial injury may be associated with the development of NADRI $[66,96]$.

Further studies show that the decline in GFR in T2DM with or without microalbuminuria is associated with an increase in carotid intimal-medial thickness, carotid stiffness, and intrarenal arterial resistance index [97], which suggest that the reduction in GFR is partly due to generalized increase in arteriosclerosis [70]. Subsequent studies showed that arteriosclerosis may contribute to decrease in renal function independently of albuminuria and may be playing pathogenic roles [58]. Arteriosclerosis is the underlying mechanisms of glomerulosclerosis [98], and diabetic patients with glomerulosclerosis present with a more rapid decline in eGFR [99]. The main renal arteries stenosis caused by atherosclerosis increases the susceptibility to kidney ischemia [100]. A proportion of patients with rapid decline of eGFR exhibited normoalbuminuria, which may be associated with ischemic kidney changes caused by the intrarenal arteries atherosclerosis [101, 102].

Moreover, interstitial fibrosis, tubular atrophy, and arteriosclerosis in renal biopsy specimens are the pathological factors to develop kidney events [56]. Besides arteriosclerosis, arteriolar hyalinosis is related to global glomerular sclerosis because it reduces the glomerular blood flow [103] and has been found to be a histological predictor for GFR decline in diabetic patients with normoalbuminuria [104].

\section{Age}

Some clinical studies of NADRI show that patients with NADRI are more likely to be older, and age is an independent risk factors for renal insufficiency in T2DM patients with normoalbuminuria $[55,66]$. This fact should probably indicate that age may play a role in the development of NADRI.

Aging can lead to various anatomical and physiological changes of the kidney, including structural changes of aging with age, declining GFR, and decreased tubular function $[105,106]$. In addition, elderly diabetic patients usually have increased underlying conditions, such as obesity, hypertension, dyslipidemia, and hyperuricemia, which may result in renal function loss and nephrosclerosis via arteriosclerosis.

More significant heterogeneity in renal structural changes of NADRI (atypical tubulointerstitial and vascular lesions) than in ADRI suggested aging may be one of the key contributors to the atypical nephropathy changes observed in NADRI and contributes to decline in kidney function independently of albuminuria [58]. In particular, hyaline arteriolosclerosis is a characteristic of 'age-related vasculopathy' and is related to global glomerular sclerosis [107], which is a histological predictor for GFR decline in normoalbuminuric patients with T2DM [104]. 


\section{Gene polymorphism}

The prevalence of NADRI varies by ethnic groups, indicating the development of the disease may involve genetic susceptibility. Polymorphism of the protein kinase $C-\beta$ gene was related to accelerated decline of eGFR in T2DM without overt proteinuria, and the T-G haplotype of protein kinase $\mathrm{C}-\beta$ gene (PRKCB1) may be a valuable predictive factor for the rapid deterioration of kidney function [108].

In addition, the relationship between polymorphism of angiotensin type 1 receptor gene and normoalbuminuric chronic kidney disease among South Indian T2DM patients was described. Compared to ADRI, the relative risk of $\mathrm{AC}$ genotype and $\mathrm{C}$ allele in NADRI was 4 times higher. Significant correlation of AGTR1 A1166C polymorphism was noted in NADRI as compared to ADRI [109].

\section{Female gender}

The effects of gender on renal injury are controversial. Lotfinejad et al. noted renal damage in diabetes was directly related to male gender, but not to female gender [110]. In vitro experiment data showed $17 \beta$-estradiol can attenuate glomerulosclerosis and renal tubulointerstitial fibrosis in streptozotocin-induced diabetes mellitus [111]. However, a study on obese mice with T2DM found that female mice had renal injury earlier than male mice [112]. Al-Trad et al. [113] suggested that diabetes may give rise to sex hormones disorder and affected estrogen receptors distribution in the renal tissues; as a result, estrogen had no protective effect on the kidney in diabetic patients but aggravated the decline in GFR. Estrogens play a part in regulating and responding to the components of RAAS [114], activation of which is harmful to renal function [115].

Epidemiological studies show that the prevalence of NADRI is higher in female gender. The female predominance may be due to sex differences in CKD risk [116]. Female gender is an independent risk factors for renal impairment [29, 36, 75, 117]. Previous study described that decreased GFR in eight normoalbuminuric longstanding T1DM women was related to worse diabetic glomerular injury [9]. Tsalamandris et al. also well described a relatively small group of normoalbuminuric long-standing diabetic largely female individuals with declined GFR [21]. These facts indicate that reduced GFR is much more common among female patients [63].

Subsequent studies have demonstrated women with diabetes are at greater risk than men for accelerated GFR decline in the absence of albuminuria [28]. This effect is best shown by UKPDS-7426 study [29], which found that during a follow-up period of up to 15 years, women were at increased risk.

\section{Immune inflammation and oxidative stress}

Tumor necrosis factor alpha (TNF- $\alpha$ ), interferon $\gamma$, interleukin (IL)-10, IL-6, KIM-1, and other inflammatory cytokines are involved in the immune inflammatory response of DKD [96, 118]. Further studies have shown proinflammatory interleukins are related to podocyte lesions and proximal tubular dysfunction in early DKD, which could play a key role in the pathogenesis of early DKD, prior to the development of albuminuria [119]. Inflammatory cytokines were associated with early kidney damage and predict progression in patients without albuminuria [120].

The concentration of serum Fas-pathways cytokines (soluble Fas and Fas ligand) and TNF- $\alpha$ (soluble TNF receptor 1, soluble TNF receptor 2) are related to reduced eGFR independent of urinary albumin excretion in diabetes $[66,121-123]$. Li et al's study found that TNF- $\alpha$ was independent risk factors for normoalbuminuric kidney insufficiency in T2DM [66]. Further studies show TNF- $\alpha$ can directly decrease glomerular blood flow and increase glomerular vasoconstriction, leading to the decline of glomerular filtration rate [124].

In addition, serum IL-17A, IL-18, and macrophage inflammatory protein 1 alpha were predictors of NADRI $[125,126]$. Urinary inflammatory cytokines, IL-1, IL-6, IL-10, TNF- $\alpha$, and interferon- $\gamma$, especially IL- 6 and IL-10, may assist in the identification of DKD in T2DM patients, even in the absence of micro- and macroalbuminuria [127]. Consequently, immune inflammation plays an important role in the decline of renal function of NADRI.

Besides immune inflammation, oxidative stress may contribute to the development of NADRI. 8-hydroxydeoxyguanosine, as a sensitive marker of intracellular oxidative stress, is more highly expressed in high intima media thickness than in normal intima media thickness and is positively related to coronary heart disease risk scores [128]. The clinical features and renal histopathologic changes study of NADRI showed that macroangiopathy was more prevalent and often accompanied by cardiovascular disease. What is more, 8-hydroxydeoxyguanosine is an independent risk factor for NADRI [66].

In addition, urinary NGAL and RBP are biomarkers for NADRI, which may be caused by inflammation and oxidative stress and lead to tubular damage $[66,129]$.

\section{Drugs}

For the past decades, the use of RAAS blockers has increased [50] and recent studies report that the values are up to $70 \%$ or more $[24,36,37,47]$. What is more, the use of RAAS blockers and prevalence of NADRI have parallelly increased. Although significant difference was not observed after ruling out the effect of RAAS blockers, 
the prevalence of NADRI was generally lower than the use of RAAS blockers was introduced [5]. Previous studies have shown that the use of RAAS blockers in diabetes can prevent the development of microalbuminuria[130, 131]. In a study of the renal structure of NADRI, 2 in 10 patients with normoalbuminuria developed microalbuminuria at 4-6 weeks after the cessation of RAAS inhibitor treatment [58]. Further studies indicate that the occurrence of NADRI is closely associated with the application of RAAS blockers [55]. Therefore, the therapeutic effect of RAAS blockers may take a part in the pathogenesis of NADRI.

At present, there are two hypotheses on the pathogenesis. One is that the application of RAAS blockers slows the progression of albuminuria in diabetes, while the decline in eGFR is not significantly improved, even possibly resulting in an acute decline of eGFR [50, 51, $55,132]$. As far as purely theoretical grounds, under certain circumstances, RAAS blockers may be deleterious, because these agents increase the susceptibility to renal ischemia due to certain causes (atherosclerosis, sepsis, immunosuppressants, etc.) via preventing the increase of efferent arteriolar resistance [100].

The other proposed mechanism is that the use of RAAS blockers in diabetes may result in a decline in the prevalence of glomerular damage and allowed the occurrence of other renal injury, such as interstitium and vascular damage, which may lead to progressive renal injury without triggering albuminuria [74].

\section{Acute kidney injury}

In diabetes, due to various factors, such as ischemia, infection, nephrotoxicity, or obstruction, acute kidney injury (AKI) often occurs in a mild and unrecognizable form, resulting in progressive decline in kidney function independent of albuminuria [133]. Onuigbo et al. also reported that once AKI occurs in diabetic patients, renal function decrease is more likely, and this is independent of albuminuria [134]. Single or recurrent AKI remarkably increases the risk of advanced CKD, and AKI is a risk factor for CKD independent of albuminuria in diabetes [135].

Several mechanisms have been proposed for the progression of AKI to CKD, such as nephron loss, inflammation, endothelial injury with vascular rarefaction and hypoxia, epigenetic changes, and cell cycle arrest in epithelial cells, ultimately leading to progressive glomerulosclerosis and tubulointerstitial fibrosis [136-139].

\section{Diagnosis}

Kidney Disease Outcome Quality Initiative (KDOQI) guidelines recommend that the diagnosis of DKD should be based on monitoring UACR or UAER,

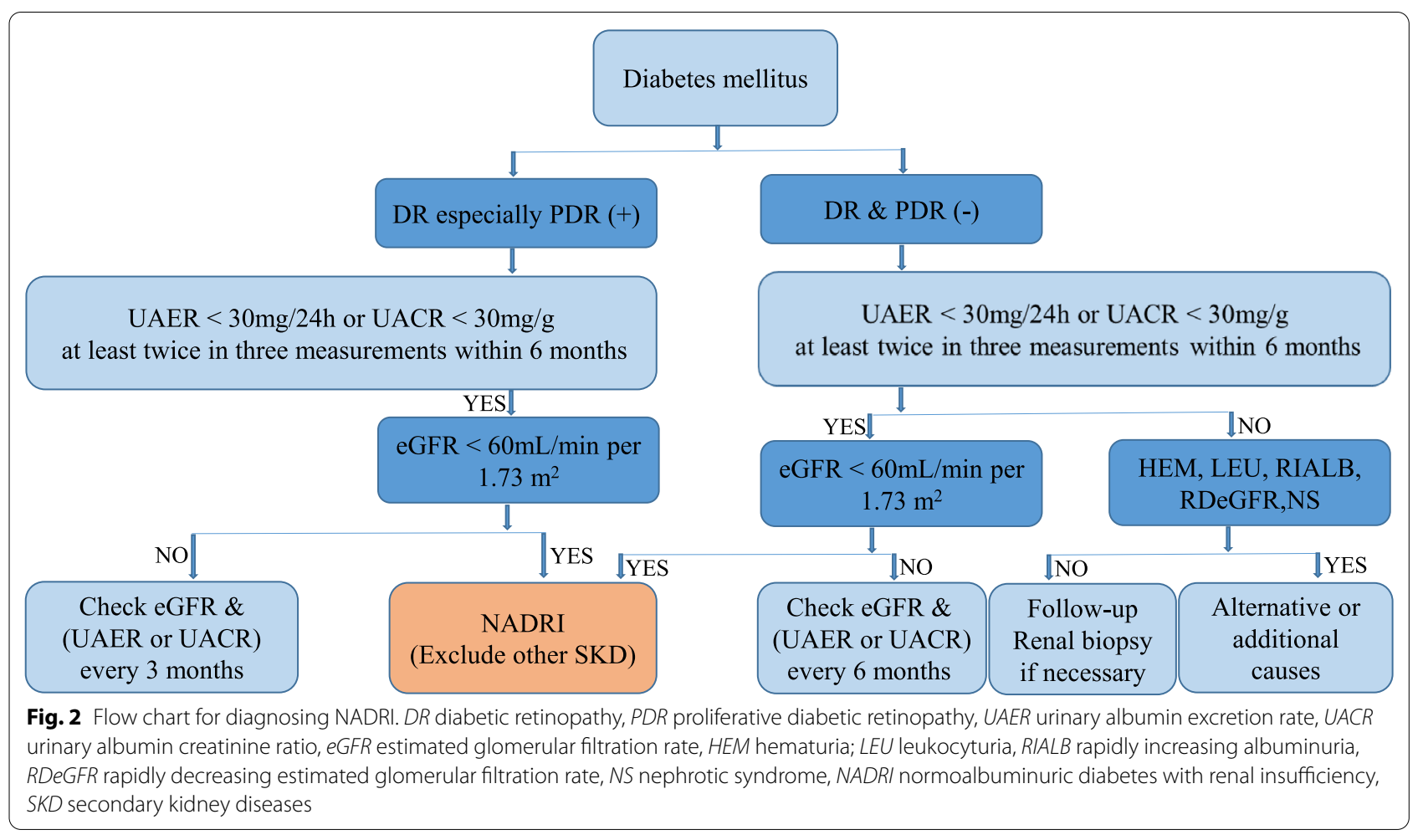


fundus changes, and evaluation of eGFR. Based on KDOQI guidelines recommendations and clinical studies of NADRI, we attempt to propose the diagnostic criteria of NADRI: (1) to meet the latest diabetes diagnostic standards of World Health Organization or American Diabetes Association (ADA); (2) to test and prove within 6 months, UAER $<30 \mathrm{mg} / 24 \mathrm{~h}$ or UAER $<20 \mu \mathrm{g} / \mathrm{min}$ or $\mathrm{UACR}<30 \mathrm{mg} / \mathrm{g}$, at least twice in three measurements, to avoid confounding by transient increases in conditions, such as exercise, fever, hematuria, urinary tract infection, and congestive heart failure[140]; (3) to detect within 6 months, eGFR $<60 \mathrm{~mL} / \mathrm{min} / 1.73 \mathrm{~m}^{2}$, at least twice in three measurements, and exclude eGFR reduction caused by AKI and other reasons; and (4) to exclude other secondary nondiabetic kidney diseases (Fig. 2).

eGFR estimation formula based on serum creatinine is generally recommended for diagnosis of DKD, including Cockcroft-Gault formula, modification of diet in renal disease formula, and CKD epidemiology collaboration (CKD-EPI) formula [141, 142]. However, serum creatinine level is susceptible to be influenced by factors, like muscle mass, dietary protein intake, hyperlipidemia, hemolysis, etc.; the sensitivity in eGFR is insufficient. Therefore, in recent years, the Kidney Disease: Improving Global Outcomes (KDIGO) and ADA proposed to use the eGFR calculation formula based on serum creatinine and cystatin $C$, such as CKD-EPI cystatin $C$ formula and CKD-EPI creatinine-cystatin C formula [143]. Consequently, according to the latest KDIGO guidelines, we recommend adding the detection of serum cystatin $C$, and the eGFR may be calculated according to the cystatin $\mathrm{C}$ and creatinine-cystatin $\mathrm{C}$ formula.

\section{Conclusion}

Epidemiological data demonstrate that NADRI is a prevalent clinical phenotype of DKD. Moreover, NADRI exhibits distinct clinical characteristics and a wide heterogeneity of histology features. Based on the studies of clinical features and renal histopathologic changes of NADRI, we attempt to propose an underlying pathogenesis model and a flow chart for diagnosing NADRI, which increases the practicality and reliability of the study. The underlying pathogenesis associated with NADRI involves multiple factors and comprises the usual suspects, including obesity, hyperlipidemia, tubulointerstitial lesion and vascular disease, age, gene polymorphism, female gender, immune inflammation and oxidative stress, drugs, and AKI, while appears to be at least partially independent of hyperglycemia and hypertension and does not exclude the possible role of hyperuricemia. Early diagnosis and a deeper understanding of pathogenesis may provide theoretical guidance for the therapy of NADRI and prevent or delay the
CKD progression, end-stage renal disease, and diabetes complications as far as possible.

Although many of factors are discussed in this review, the list is not exhaustive. Multilevel, multicenter, largesample clinical studies are needed to further clarify the pathogenesis of the disease, discover specific biomarkers, establish clear and precise laboratory diagnostic standards for the disease, and provide an important theoretical basis for preventing the occurrence, development, early intervention, and treatment of the disease.

\section{Abbreviations \\ DKD: Diabetic kidney disease; eGFR: Estimated glomerular filtration rate; UAER: Urinary albumin excretion rate; UACR: Urinary albumin creatinine ratio; NADRI: Normoalbuminuric diabetes with renal insufficiency; CKD: Chronic kidney disease; ADRI: Albuminuric diabetes with renal insufficiency; T1DM: Type 1 diabetes mellitus; T2DM: Type 2 diabetes mellitus; RAAS: Renin-angiotensin- aldosterone system; HbA1c: Hemoglobin A1c; GFR: Glomerular filtration rate; IL: Interleukin; IFTA: Interstitial fibrosis and tubular atrophy; KIM-1: Kidney injury molecule-1; NGAL: Neutrophil gelatinase-associated lipocalin; RBP: Retinol- binding protein; AKI: Acute kidney injury; KDOQI: Kidney Disease Outcome Quality Initiative; ADA: American Diabetes Association; KDIGO: Kidney Disease: Improving Global Outcomes.}

\section{Acknowledgements}

This work was supported by the National Natural Science Foundation of China (No. 81970583 and No.82060138), the Nature Science Foundation of Jiangxi Province (No. 2020BABL206025), and the Projects in the Second Affiliated Hospital of Nanchang University (No. 2019YNLZ12008).

\section{Authors' contributions}

LD and WL contributed to this work. All authors read and approved the final manuscript.

\section{Funding}

This work was supported by the National Natural Science Foundation of China (No. 81970583, Gaosi Xu and No. 82060138, Gaosi Xu,), the Nature Science Foundation of Jiangxi Province (No. 2020BABL206025, Gaosi Xu), and the Projects in the Second Affiliated Hospital of Nanchang University (No. 2019YNLZ12008, Gaosi Xu).

Availability of data and materials

All data were collected from the publication articles.

\section{Declarations}

Ethics approval and consent to participate

This manuscript is a review article and does not involve a research protocol requiring approval by the relevant institutional review board or ethics committee.

Consent for publication

Manuscript is approved by all authors for publication.

Competing interests

Le Deng, Wenjie Li, and Gaosi Xu declare that they have no conflict of interest.

Received: 30 September 2021 Accepted: 16 November 2021

Published online: 11 December 2021 


\section{References}

1. Chen C, Wang C, Hu C, Han Y, Zhao L, Zhu X, et al. Normoalbuminuric diabetic kidney disease. Front Med. 2017;11(3):310-8.

2. Mottl AK, Kwon KS, Mauer M, Mayer-Davis EJ, Hogan SL, Kshirsagar AV. Normoalbuminuric diabetic kidney disease in the U.S. population. J Diabetes Complications. 2013;27(2):123-7.

3. Lacquaniti A, Donato V, Pintaudi B, Di Vieste G, Chirico V, Buemi A, et al. "Normoalbuminuric" diabetic nephropathy: tubular damage and NGAL. Acta Diabetol. 2013;50(6):935-42.

4. Macisaac RJ, Jerums G. Diabetic kidney disease with and without albuminuria. Curr Opin Nephrol Hypertens. 2011;20(3):246-57.

5. Maclsaac RJ, Tsalamandris C, Panagiotopoulos S, Smith TJ, McNeil KJ Jerums $\mathrm{G}$. Nonalbuminuric renal insufficiency in type 2 diabetes. Diabetes Care. 2004;27(1):195-200.

6. Viazzi F, Russo GT, Ceriello A, Fioretto P, Giorda C, De Cosmo S, et al. Natural history and risk factors for diabetic kidney disease in patients with T2D: lessons from the AMD-annals. J Nephrol. 2019;32(4):517-25.

7. Penno G, Solini A, Orsi E, Bonora E, Fondelli C, Trevisan R, et al. Non-albuminuric renal impairment is a strong predictor of mortality in individuals with type 2 diabetes: the Renal Insufficiency And Cardiovascular Events (RIACE) Italian multicentre study. Diabetologia. 2018;61(11):2277-89.

8. Pugliese G, Penno G, Natali A, Barutta F, Di PS, Reboldi G, et al. Diabetic kidney disease: new clinical and therapeutic issues. Joint position statement of the Italian Diabetes Society and the Italian Society of Nephrology on "The natural history of diabetic kidney disease and treatment of hyperglycemia in patients with type 2 diabetes and impaired renal function." J Nephrol. 2020;33(1):9-35.

9. Lane PH, Steffes MW, Mauer SM. Glomerular structure in IDDM women with low glomerular filtration rate and normal urinary albumin excretion. Diabetes. 1992;41(5):581-6.

10. Kramer H, Boucher RE, Leehey D, Fried L, Wei G, Greene T, et al. Increasing mortality in adults with diabetes and low estimated glomerular filtration rate in the absence of albuminuria. Diabetes Care. 2018;41(4):775-81.

11. Koye DN, Magliano DJ, Reid CM, Jepson C, Feldman HI, Herman WH, et al. Risk of progression of nonalbuminuric CKD to end-stage kidney disease in people with diabetes: the CRIC (Chronic Renal Insufficiency Cohort) study. Am J Kidney Dis. 2018;72(5):653-61.

12. Yokoyama H, Araki SI, Kawai K, Yamazaki K, Shirabe SI, Sugimoto H, et al. The prognosis of patients with type 2 diabetes and nonalbuminuric diabetic kidney disease is not always poor: implication of the effects of coexisting macrovascular complications (JDDM 54). Diabetes Care. 2020;43(5):1102-10.

13. Yamanouchi M, Furuichi K, Hoshino J, Toyama T, Hara A, Shimizu M, et al. Nonproteinuric versus proteinuric phenotypes in diabetic kidney disease: a propensity score-matched analysis of a nationwide biopsybased cohort study. Diabetes Care. 2019;42(5):891-902.

14. Pichaiwong W, Homsuwan W, Leelahavanichkul A. The prevalence of normoalbuminuria and renal impairment in type 2 diabetes mellitus. Clin Nephrol. 2019;92(2):73-80.

15. Lamacchia O, Viazzi F, Fioretto P, Mirijello A, Giorda C, Ceriello A, et al. Normoalbuminuric kidney impairment in patients with T1DM: insights from annals initiative. Diabetol Metab Syndr. 2018;10:60

16. Buyadaa O, Magliano DJ, Salim A, Koye DN, Shaw JE. Risk of rapid kidney function decline, all-cause mortality, and major cardiovascular events in nonalbuminuric chronic kidney disease in type 2 diabetes. Diabetes Care. 2020:43(1):122-9.

17. Ito H, Antoku S, Izutsu T, Kusano E, Matsumoto S, Yamasaki T, et al. The prognosis of subjects showing a reduced estimated glomerular filtration rate without albuminuria in Japanese patients with type 2 diabetes: a cohort study for diabetic kidney disease. Clin Exp Nephrol. 2020;24(11):1033-43.

18. Rigalleau V, Lasseur C, Raffaitin C, Beauvieux MC, Barthe N, Chauveau P, et al. Normoalbuminuric renal-insufficient diabetic patients: a lower-risk group. Diabetes Care. 2007:30(8):2034-9.

19. Klimontov W, Korbut Al. Albuminuric and non-albuminuric patterns of chronic kidney disease in type 2 diabetes. Diabetes Metab Syndr. 2019;13(1):474-9.

20. Vistisen D, Andersen GS, Hulman A, Persson F, Rossing P, Jørgensen ME. Progressive decline in estimated glomerular filtration rate in patients with diabetes after moderate loss in kidney function-even without albuminuria. Diabetes Care. 2019;42(10):1886-94.

21. Tsalamandris C, Allen TJ, Gilbert RE, Sinha A, Panagiotopoulos S, Cooper $M E$, et al. Progressive decline in renal function in diabetic patients with and without albuminuria. Diabetes. 1994;43(5):649-55.

22. Kramer HJ, Nguyen QD, Curhan G, Hsu CY. Renal insufficiency in the absence of albuminuria and retinopathy among adults with type 2 diabetes mellitus. JAMA. 2003;289(24):3273-7.

23. Thomas MC, Macisaac RJ, Jerums G, Weekes A, Moran J, Shaw JE, et al. Nonalbuminuric renal impairment in type 2 diabetic patients and in the general population (national evaluation of the frequency of renal impairment cO-existing with NIDDM [NEFRON] 11). Diabetes Care. 2009;32(8):1497-502.

24. Penno G, Solini A, Bonora E, Fondelli C, Orsi E, Zerbini G, et al. Clinical significance of nonalbuminuric renal impairment in type 2 diabetes. J Hypertens. 2011;29(9):1802-9.

25. Parving $\mathrm{HH}$, Lewis JB, Ravid M, Remuzzi G, Hunsicker LG. Prevalence and risk factors for microalbuminuria in a referred cohort of type II diabetic patients: a global perspective. Kidney Int. 2006;69(11):2057-63.

26. So WY, Kong AP, Ma RC, Ozaki R, Szeto CC, Chan NN, et al. Glomerular filtration rate, cardiorenal end points, and all-cause mortality in type 2 diabetic patients. Diabetes Care. 2006;29(9):2046-52.

27. Boronat M, García-Cantón C, Quevedo V, Lorenzo DL, López-Ríos L, Batista F, et al. Non-albuminuric renal disease among subjects with advanced stages of chronic kidney failure related to type 2 diabetes mellitus. Ren Fail. 2014;36(2):166-70.

28. Yokoyama H, Sone H, Oishi M, Kawai K, Fukumoto Y, Kobayashi M. Prevalence of albuminuria and renal insufficiency and associated clinical factors in type 2 diabetes: the Japan Diabetes Clinical Data Management study (JDDM15). Nephrol Dial Transplant. 2009;24(4):1212-9.

29. Retnakaran R, Cull CA, Thorne Kl, Adler Al, Holman RR. Risk factors for renal dysfunction in type 2 diabetes: U.K. Prospective Diabetes Study 74. Diabetes. 2006;55(6):1832-9.

30. Laranjinha I, Matias P, Mateus S, Aguiar F, Pereira P, Perneta SM, et al. Diabetic kidney disease: is there a non-albuminuric phenotype in type 2 diabetic patients? Nefrologia. 2016;36(5):503-9.

31. Guo K, Zhang L, Zhao F, Lu J, Pan P, Yu H, et al. Prevalence of chronic kidney disease and associated factors in Chinese individuals with type 2 diabetes: cross-sectional study. J Diabetes Complications. 2016;30(5):803-10.

32. Afkarian M, Sachs MC, Kestenbaum B, Hirsch IB, Tuttle KR, Himmelfarb $J$, et al. Kidney disease and increased mortality risk in type 2 diabetes. J Am Soc Nephrol. 2013;24(2):302-8.

33. Bailey RA, Wang Y, Zhu V, Rupnow MF. Chronic kidney disease in US adults with type 2 diabetes: an updated national estimate of prevalence based on Kidney Disease: Improving Global Outcomes (KDIGO) staging. BMC Res Notes. 2014;7:415.

34. Dwyer JP, Parving HH, Hunsicker LG, Ravid M, Remuzzi G, Lewis JB. Renal dysfunction in the presence of normoalbuminuria in Type 2 diabetes: results from the DEMAND Study. Cardiorenal Med. 2012;2(1):1-10.

35. Thomas MC, Weekes AJ, Broadley OJ, Cooper ME, Mathew TH. The burden of chronic kidney disease in Australian patients with type 2 diabetes (the NEFRON study). Med J Aust. 2006:185(3):140-4.

36. De Cosmo S, Rossi MC, Pellegrini F, Lucisano G, Bacci S, Gentile S, et al. Kidney dysfunction and related cardiovascular risk factors among patients with type 2 diabetes. Nephrol Dial Transplant. 2014;29(3):657-62.

37. Afghahi H, Miftaraj M, Svensson AM, Hadimeri H, Gudbjörnsdottir S, Eliasson B, et al. Ongoing treatment with renin-angiotensinaldosterone-blocking agents does not predict normoalbuminuric renal impairment in a general type 2 diabetes population. J Diabetes Complications. 2013;27(3):229-34.

38. Hill CJ, Cardwell CR, Patterson CC, Maxwell AP, Magee GM, Young RJ, et al. Chronic kidney disease and diabetes in the national health service: a cross-sectional survey of the U.K. national diabetes audit. Diabet Med. 2014;31(4):448-54.

39. Gao B, Wu S, Wang J, Yang C, Chen S, Hou J, et al. Clinical features and long-term outcomes of diabetic kidney disease-a prospective cohort study from China. J Diabetes Complications. 2019;33(1):39-45.

40. Rodriguez-Poncelas A, Garre-Olmo J, Franch-Nadal J, Diez-Espino J, Mundet-Tuduri X, Barrot-De LPJ, et al. Prevalence of chronic kidney 
disease in patients with type 2 diabetes in Spain: PERCEDIME2 study. BMC Nephrol. 2013;14:46.

41. Bramlage $P$, Lanzinger $S$, van Mark G, Hess E, Fahrner S, Heyer C, et al. Patient and disease characteristics of type-2 diabetes patients with or without chronic kidney disease: an analysis of the German DPV and DIVE databases. Cardiovasc Diabetol. 2019;18(1):33.

42. Drury PL, Ting R, Zannino D, Ehnholm C, Flack J, Whiting M, et al. Estimated glomerular filtration rate and albuminuria are independent predictors of cardiovascular events and death in type 2 diabetes mellitus: the Fenofibrate Intervention and Event Lowering in Diabetes (FIELD) study. Diabetologia. 2011;54(1):32-43.

43. Ninomiya T, Perkovic V, de Galan BE, Zoungas S, Pillai A, Jardine $M$, et al. Albuminuria and kidney function independently predict cardiovascular and renal outcomes in diabetes. J Am Soc Nephrol. 2009;20(8):1813-21.

44. Tobe SW, Clase CM, Gao P, McQueen M, Grosshennig A, Wang X, et al. Cardiovascular and renal outcomes with telmisartan, ramipril, or both in people at high renal risk: results from the ONTARGET and TRANSCEND studies. Circulation. 2011;123(10):1098-107.

45. Bakris GL, Sarafidis PA, Weir MR, Dahlöf B, Pitt B, Jamerson K, et al. Renal outcomes with different fixed-dose combination therapies in patients with hypertension at high risk for cardiovascular events (ACCOMPLISH): a prespecified secondary analysis of a randomised controlled trial. Lancet. 2010:375(9721):1173-81.

46. Molitch ME, Steffes M, Sun W, Rutledge B, Cleary P, de Boer IH, et al. Development and progression of renal insufficiency with and without albuminuria in adults with type 1 diabetes in the diabetes control and complications trial and the epidemiology of diabetes interventions and complications study. Diabetes Care. 2010;33(7):1536-43.

47. Thorn LM, Gordin D, Harjutsalo V, Hägg S, Masar R, Saraheimo M, et al. The presence and consequence of nonalbuminuric chronic kidney disease in patients with type 1 diabetes. Diabetes Care. 2015;38(11):2128-33.

48. Pacilli A, Viazzi F, Fioretto P, Giorda C, Ceriello A, Genovese S, et al. Epidemiology of diabetic kidney disease in adult patients with type 1 diabetes in Italy: the AMD-Annals initiative. Diabetes Metab Res Rev. 2017;33(4):e2873.

49. Penno G, Russo E, Garofolo M, Daniele G, Lucchesi D, Giusti L, et al. Evidence for two distinct phenotypes of chronic kidney disease in individuals with type 1 diabetes mellitus. Diabetologia. 2017;60(6):1102-13.

50. Afkarian M, Zelnick LR, Hall YN, Heagerty PJ, Tuttle K, Weiss NS, et al. Clinical manifestations of kidney disease among US adults with diabetes, 1988-2014. JAMA. 2016;316(6):602-10.

51. Kume S, Araki SI, Ugi S, Morino K, Koya D, Nishio Y, et al. Secular changes in clinical manifestations of kidney disease among Japanese adults with type 2 diabetes from 1996 to 2014. J Diabetes Investig. 2019;10(4):1032-40

52. Andrésdóttir $G$, Jensen ML, Carstensen $B$, Parving HH, Hovind $P$, Hansen TW, et al. Improved prognosis of diabetic nephropathy in type 1 diabetes. Kidney Int. 2015;87(2):417-26.

53. Pavkov ME, Mason CC, Bennett PH, Curtis JM, Knowler WC, Nelson $\mathrm{RG}$. Change in the distribution of albuminuria according to estimated glomerular filtration rate in Pima Indians with type 2 diabetes. Diabetes Care. 2009;32(10):1845-50.

54. Marshall SM. Natural history and clinical characteristics of CKD in type 1 and type 2 diabetes mellitus. Adv Chronic Kidney Dis. 2014;21(3):267-72.

55. Dai Q, Chen N, Zeng L, Lin XJ, Jiang FX, Zhuang XJ, et al. Clinical features of and risk factors for normoalbuminuric diabetic kidney disease in hospitalized patients with type 2 diabetes mellitus: a retrospective cross-sectional study. BMC Endocr Disord. 2021;21(1):104

56. Shimizu M, Furuichi K, Toyama T, Kitajima S, Hara A, Kitagawa K, et al. Long-term outcomes of Japanese type 2 diabetic patients with biopsyproven diabetic nephropathy. Diabetes Care. 2013;36(11):3655-62.

57. An JH, Cho YM, Yu HG, Jang HC, Park KS, Kim SY, et al. The clinical characteristics of normoalbuminuric renal insufficiency in Korean type 2 diabetic patients: a possible early stage renal complication. J Korean Med Sci. 2009;24:S75-81.

58. Ekinci El, Jerums G, Skene A, Crammer P, Power D, Cheong KY, et al. Renal structure in normoalbuminuric and albuminuric patients with type 2 diabetes and impaired renal function. Diabetes Care. 2013;36(11):3620-6.

59. Kramer CK, Leitão CB, Pinto LC, Silveiro SP, Gross JL, Canani LH. Clinical and laboratory profile of patients with type 2 diabetes with low glomerular filtration rate and normoalbuminuria. Diabetes Care. 2007;30(8):1998-2000.

60. Ito H, Takeuchi Y, Ishida H, Antoku S, Abe M, Mifune M, et al. High frequencies of diabetic micro- and macroangiopathies in patients with type 2 diabetes mellitus with decreased estimated glomerular filtration rate and normoalbuminuria. Nephrol Dial Transplant. 2010;25(4):1161-7.

61. Klessens CQ, Woutman TD, Veraar KA, Zandbergen M, Valk EJ, Rotmans $J$, et al. An autopsy study suggests that diabetic nephropathy is underdiagnosed. Kidney Int. 2016;90(1):149-56.

62. Yagil C, Barak A, Ben-Dor D, Rosenmann E, Bernheim J, Rosner M, et al. Nonproteinuric diabetes-associated nephropathy in the Cohen rat model of type 2 diabetes. Diabetes. 2005;54(5):1487-96.

63. Caramori ML, Fioretto P, Mauer M. Low glomerular filtration rate in normoalbuminuric type 1 diabetic patients: an indicator of more advanced glomerular lesions. Diabetes. 2003;52(4):1036-40.

64. Walker JD, Close CF, Jones SL, Rafftery M, Keen H, Viberti G, et al. Glomerular structure in type-1 (insulin-dependent) diabetic patients with normo- and microalbuminuria. Kidney Int. 1992;41(4):741-8.

65. Shimizu M, Furuichi K, Yokoyama H, Toyama T, Iwata Y, Sakai N, et al. Kidney lesions in diabetic patients with normoalbuminuric renal insufficiency. Clin Exp Nephrol. 2014;18(2):305-12.

66. Li A, Yi B, Liu Y, Wang J, Dai Q, Huang Y, et al. Urinary NGAL and RBP are biomarkers of normoalbuminuric renal insufficiency in Type 2 diabetes mellitus. J Immunol Res. 2019;2019:5063089.

67. Nowak N, Skupien J, Niewczas MA, Yamanouchi M, Major M, Croall S, et al. Increased plasma kidney injury molecule-1 suggests early progressive renal decline in non-proteinuric patients with type 1 diabetes. KIDNEY INT. 2016;89(2):459-67.

68. Lee HW, Jo AR, Yi DW, Kang YH, Son SM. Prevalent rate of nonalbuminuric renal insufficiency and its association with cardiovascular disease event in korean type 2 diabetes. Endocrinol Metab (Seoul). 2016;31(4):577-85.

69. Li YH, Sheu WH, Lee IT. Effects of retinopathy and chronic kidney disease on long-term mortality in type 2 diabetic inpatients with normal urinary albumin or protein: a retrospective cohort study. BMJ Open. 2018;8(7):e21655

70. Maclsaac RJ, Panagiotopoulos S, McNeil KJ, Smith TJ, Tsalamandris C $\mathrm{Hao} \mathrm{H}$, et al. Is nonalbuminuric renal insufficiency in type 2 diabetes related to an increase in intrarenal vascular disease? Diabetes Care. 2006;29(7):1560-6.

71. Yang Y, Xu P, Liu Y, Chen X, He Y, Feng J. Vascular inflammation, atherosclerosis, and lipid metabolism and the occurrence of non-high albuminuria diabetic kidney disease: a cross-sectional study. Diab Vasc Dis Res. 2021:18(1):1139913396.

72. Pugliese G, Penno G, Natali A, Barutta F, Di Paolo S, Reboldi G, et al. Diabetic kidney disease: New clinical and therapeutic issues. Joint position statement of the Italian Diabetes Society and the Italian Society of Nephrology on "The natural history of diabetic kidney disease and treatment of hyperglycemia in patients with type 2 diabetes and impaired renal function." Nutr Metab Cardiovasc Dis. 2019;29(11):1127-50

73. Schmieder RE, Messerli FH, Garavaglia G, Nunez B. Glomerular hyperfiltration indicates early target organ damage in essential hypertension. JAMA. 1990;264(21):2775-80.

74. Bolignano D, Zoccali C. Non-proteinuric rather than proteinuric renal diseases are the leading cause of end-stage kidney disease. Nephrol Dial Transplant. 2017;32(suppl 2):i194-9.

75. Afghahi H, Cederholm J, Eliasson B, Zethelius B, Gudbjörnsdottir S, Hadimeri $\mathrm{H}$, et al. Risk factors for the development of albuminuria and renal impairment in type 2 diabetes-the Swedish National Diabetes Register (NDR). Nephrol Dial Transplant. 2011;26(4):1236-43.

76. Kobayashi H, Tokudome G, Hara Y, Sugano N, Endo S, Suetsugu Y, et al. Insulin resistance is a risk factor for the progression of chronic kidney disease. Clin Nephrol. 2009;71(6):643-51.

77. Sarafidis PA, Ruilope LM. Insulin resistance, hyperinsulinemia, and renal injury: mechanisms and implications. Am J Nephrol. 2006;26(3):232-44. 
78. Persson F, Rossing P, Hovind P, Stehouwer CD, Schalkwijk CG, Tarnow $L$, et al. Endothelial dysfunction and inflammation predict development of diabetic nephropathy in the Irbesartan in Patients with Type 2 Diabetes and Microalbuminuria (IRMA 2) study. Scand J Clin Lab Invest. 2008:68(8):731-8.

79. Bash LD, Selvin E, Steffes M, Coresh J, Astor BC. Poor glycemic control in diabetes and the risk of incident chronic kidney disease even in the absence of albuminuria and retinopathy: Atherosclerosis Risk in Communities (ARIC) Study. Arch Intern Med. 2008;168(22):2440-7.

80. Caramori ML, Parks A, Mauer M. Renal lesions predict progression of diabetic nephropathy in type 1 diabetes. J Am Soc Nephrol. 2013;24(7):1175-81.

81. Schrier RW, Estacio RO, Esler A, Mehler P. Effects of aggressive blood pressure control in normotensive type 2 diabetic patients on albuminuria, retinopathy and strokes. Kidney Int. 2002;61 (3):1086-97.

82. Muntner P, Coresh J, Smith JC, Eckfeldt J, Klag MJ. Plasma lipids and risk of developing renal dysfunction: the atherosclerosis risk in communities study. Kidney Int. 2000;58(1):293-301.

83. Diamond JR, Karnovsky MJ. Focal and segmental glomerulosclerosis: analogies to atherosclerosis. Kidney Int. 1988;33(5):917-24.

84. Lam KS, Cheng IK, Janus ED, Pang RW. Cholesterol-lowering therapy may retard the progression of diabetic nephropathy. Diabetologia. 1995;38(5):604-9.

85. Chang YH, Lei CC, Lin KC, Chang DM, Hsieh CH, Lee YJ. Serum uric acid level as an indicator for CKD regression and progression in patients with type 2 diabetes mellitus-a 4.6-year cohort study. Diabetes Metab Res Rev. 2016;32(6):557-64.

86. Gu L, Huang L, Wu H, Lou Q, Bian R. Serum uric acid to creatinine ratio: a predictor of incident chronic kidney disease in type 2 diabetes mellitus patients with preserved kidney function. Diab Vasc Dis Res. 2017;14(3):221-5.

87. Pilemann-Lyberg S, Hansen TW, Tofte N, Winther SA, Theilade S, Ahluwalia TS, et al. Uric acid is an independent risk factor for decline in kidney function, cardiovascular events, and mortality in patients with type 1 diabetes. Diabetes Care. 2019;42(6):1088-94.

88. Khadka M, Pantha B, Karki L. Correlation of uric acid with glomerular filtration rate in chronic kidney disease. JNMA J Nepal Med Assoc. 2018:56(212):724-7.

89. Wang J, Yu Y, Li X, Li D, Xu C, Yuan J, et al. Serum uric acid levels and decreased estimated glomerular filtration rate in patients with type 2 diabetes: a cohort study and meta-analysis. Diabetes Metab Res Rev. 2018;34(7):e3046.

90. Qin Q, Qian Y, Zhu G, Fan W, Niu J, Gu Y. the correlation between serum uric acid and renal function in elderly Chinese diabetes with normoalbuminuria. Int J Endocrinol. 2019;2019:1435875.

91. Rosolowsky ET, Niewczas MA, Ficociello LH, Perkins BA, Warram JH, Krolewski AS. Between hyperfiltration and impairment: demystifying early renal functional changes in diabetic nephropathy. Diabetes Res Clin Pract. 2008;82(Suppl 1):S46-53.

92. Romi MM, Arfian N, Tranggono U, Setyaningsih W, Sari D. Uric acid causes kidney injury through inducing fibroblast expansion, Endothelin-1 expression, and inflammation. BMC Nephrol. 2017;18(1):326.

93. Hanai K, Tauchi E, Nishiwaki Y, Mori T, Yokoyama Y, Uchigata Y, et al. Effects of uric acid on kidney function decline differ depending on baseline kidney function in type 2 diabetic patients. Nephrol Dial Transplant. 2019;34(8):1328-35.

94. Afkarian M, Polsky S, Parsa A, Aronson R, Caramori ML, Cherney DZ, et al. Preventing early renal loss in diabetes (PERL) study: a randomized double-blinded trial of allopurinol-rationale, design, and baseline data. Diabetes Care. 2019;42(8):1454-63.

95. Taft JL, Nolan CJ, Yeung SP, Hewitson TD, Martin FI. Clinical and histological correlations of decline in renal function in diabetic patients with proteinuria. Diabetes. 1994;43(8):1046-51.

96. Nowak N, Skupien J, Smiles AM, Yamanouchi M, Niewczas MA, Galecki AT, et al. Markers of early progressive renal decline in type 2 diabetes suggest different implications for etiological studies and prognostic tests development. Kidney Int. 2018;93(5):1198-206.

97. Taniwaki H, Nishizawa Y, Kawagishi T, Ishimura E, Emoto M, Okamura $T$, et al. Decrease in glomerular filtration rate in Japanese patients with type 2 diabetes is linked to atherosclerosis. Diabetes Care. 1998;21(11):1848-55.
98. Krolewski AS, Skupien J, Rossing P, Warram JH. Fast renal decline to end-stage renal disease: an unrecognized feature of nephropathy in diabetes. Kidney Int. 2017;91(6):1300-11.

99. Jiang G, Luk A, Tam C, Xie F, Carstensen B, Lau E, et al. Progression of diabetic kidney disease and trajectory of kidney function decline in Chinese patients with Type 2 diabetes. Kidney Int. 2019;95(1):178-87.

100. Abuelo JG. Normotensive ischemic acute renal failure. N Engl J Med. 2007;357(8):797-805.

101. Seo DH, Kim SH, Song JH, Hong S, Suh YJ, Ahn SH, et al. Presence of carotid plaque is associated with rapid renal function decline in patients with type 2 diabetes mellitus and normal renal function. Diabetes Metab J. 2019;43(6):840-53.

102. Yamashita T, Makino H, Nakatani R, Ohata Y, Miyamoto Y, Kishimoto I. Renal insufficiency without albuminuria is associated with peripheral artery atherosclerosis and lipid metabolism disorders in patients with type 2 diabetes. J Atheroscler Thromb. 2013;20(11):790-7.

103. Harris RD, Steffes MW, Bilous RW, Sutherland DE, Mauer SM. Global glomerular sclerosis and glomerular arteriolar hyalinosis in insulin dependent diabetes. Kidney Int. 1991;40(1):107-14.

104. Moriya T, Omura K, Matsubara M, Yoshida Y, Hayama K, Ouchi M. Arteriolar hyalinosis predicts increase in albuminuria and GFR decline in normo- and microalbuminuric japanese patients with type 2 diabetes. Diabetes Care. 2017;40(10):1373-8.

105. O'Sullivan ED, Hughes J, Ferenbach DA. Renal aging: causes and consequences. J Am Soc Nephrol. 2017;28(2):407-20.

106. Hommos MS, Glassock RJ, Rule AD. Structural and functional changes in human kidneys with healthy aging. J Am Soc Nephrol. 2017;28(10):2838-44.

107. Silva FG. The aging kidney: a review — part I. Int Urol Nephrol. 2005;37(1):185-205.

108. Araki S, Haneda M, Sugimoto T, Isono M, Isshiki K, Kashiwagi A, et al. Polymorphisms of the protein kinase C-beta gene (PRKCB1) accelerate kidney disease in type 2 diabetes without overt proteinuria. Diabetes Care. 2006;29(4):864-8.

109. Viswanathan V, Krishnamoorthy E, Kumpatla S, Lunghar B, Soni A, Rani A. Clinical and biochemical characteristics and the association of angiotensin type 1 receptor with normoalbuminuric chronic kidney disease among South Indian type 2 diabetes population. Int J Diabetes Dev C. 2019;39(2):254-61.

110. Lotfinejad M, Rashedi A, Amirkhanlou S. The survey of relationship between resistance index of renal artery and albuminuria in diabetic patients referring to Shahid Sayyad Shirazi Hospital, 2017 to 2018. Iran J Kidney Dis. 2020;14(5):358-64.

111. Dixon A, Maric C. 17beta-Estradiol attenuates diabetic kidney disease by regulating extracellular matrix and transforming growth factorbeta protein expression and signaling. Am J Physiol Renal Physiol. 2007;293(5):F1678-90.

112. Johnson PR, Stern JS, Horwitz BA, Harris RJ, Greene SF. Longevity in obese and lean male and female rats of the Zucker strain: prevention of hyperphagia. Am J Clin Nutr. 1997;66(4):890-903.

113. Al-Trad B, Ashankyty IM, Alaraj M. Progesterone ameliorates diabetic nephropathy in streptozotocin-induced diabetic Rats. Diabetol Metab Syndr. 2015;7:97.

114. Chidambaram M, Duncan JA, Lai VS, Cattran DC, Floras JS, Scholey JW, et al. Variation in the renin angiotensin system throughout the normal menstrual cycle. J Am Soc Nephrol. 2002;13(2):446-52.

115. Hostetter TH. Prevention of the development and progression of renal disease. J Am Soc Nephrol. 2003;14(7 Suppl 2):S144-7.

116. Grams ME, Chow EK, Segev DL, Coresh J. Lifetime incidence of CKD stages 3-5 in the United States. Am J Kidney Dis. 2013;62(2):245-52.

117. Porrini E, Ruggenenti P, Mogensen CE, Barlovic DP, Praga M, Cruzado JM, et al. Non-proteinuric pathways in loss of renal function in patients with type 2 diabetes. Lancet Diabetes Endocrinol. 2015;3(5):382-91.

118. Sun L, Kanwar YS. Relevance of TNF-a in the context of other inflammatory cytokines in the progression of diabetic nephropathy. Kidney Int. 2015;88(4):662-5.

119. Milas O, Gadalean F, Vlad A, Dumitrascu V, Velciov S, Gluhovschi C, et al. Pro-inflammatory cytokines are associated with podocyte damage and proximal tubular dysfunction in the early stage of diabetic kidney disease in type 2 diabetes mellitus patients. J Diabetes Complications. 2020;34(2):107479. 
120. Phanish MK, Chapman AN, Yates S, Price R, Hendry BM, Roderick PJ, et al. Evaluation of urinary biomarkers of proximal tubular injury, inflammation, and fibrosis in patients with albuminuric and nonalbuminuric diabetic kidney disease. Kidney Int Rep. 2021;6(5):1355-67.

121. Niewczas MA, Ficociello LH, Johnson AC, Walker W, Rosolowsky ET, Roshan B, et al. Serum concentrations of markers of TNFalpha and Fasmediated pathways and renal function in nonproteinuric patients with type 1 diabetes. Clin J Am Soc Nephrol. 2009;4(1):62-70.

122. Gohda T, Nishizaki Y, Murakoshi M, Nojiri S, Yanagisawa N, Shibata T, et al. Clinical predictive biomarkers for normoalbuminuric diabetic kidney disease. Diabetes Res Clin Pract. 2018;141:62-8.

123. Carlsson AC, Östgren CJ, Nystrom FH, Länne T, Jennersjö P, Larsson A, et al. Association of soluble tumor necrosis factor receptors 1 and 2 with nephropathy, cardiovascular events, and total mortality in type 2 diabetes. Cardiovasc Diabetol. 2016;15:40.

124. Navarro JF, Mora-Fernández C. The role of TNF-alpha in diabetic nephropathy: pathogenic and therapeutic implications. Cytokine Growth Factor Rev. 2006;17(6):441-50.

125. Klimontov W, Korbut Al, Orlov NB, Dashkin MV, Konenkov VI. Multiplex bead array assay of a panel of circulating cytokines and growth factors in patients with albuminuric and non-albuminuricdiabetic kidney disease. J Clin Med. 2020;9(9):3006

126. Al-Rubeaan K, Nawaz SS, Youssef AM, Al GM, Siddiqui K. IL-18, VCAM-1 and P-selectin as early biomarkers in normoalbuminuric Type 2 diabetes patients. Biomark Med. 2019;13(6):467-78.

127. Sangoi MB, de Carvalho JA, Tatsch E, Hausen BS, Bollick YS, Londero SW, et al. Urinary inflammatory cytokines as indicators of kidney damage in type 2 diabetic patients. Clin Chim Acta. 2016;460:178-83.

128. Nishikawa T, Sasahara T, Kiritoshi S, Sonoda K, Senokuchi T, Matsuo T, et al. Evaluation of urinary 8-hydroxydeoxy-guanosine as a novel biomarker of macrovascular complications in type 2 diabetes. Diabetes Care. 2003;26(5):1507-12.

129. Li RX, Yiu WH, Wu HJ, Wong DW, Chan LY, Lin M, et al. BMP7 reduces inflammation and oxidative stress in diabetic tubulopathy. Clin Sci (Lond). 2015;128(4):269-80.

130. Persson F, Lindhardt M, Rossing P, Parving HH. Prevention of microalbuminuria using early intervention with renin-angiotensin system inhibitors in patients with type 2 diabetes: a systematic review. J Renin Angiotensin Aldosterone Syst. 2016. https://doi.org/10.1177/14703 20316652047

131. Ruggenenti P, Fassi A, llieva AP, Bruno S, lliev IP, Brusegan V, et al. Preventing microalbuminuria in type 2 diabetes. N Engl I Med. 2004;351(19):1941-51.

132. Clase CM, Barzilay J, Gao P, Smyth A, Schmieder RE, Tobe S, et al. Acute change in glomerular filtration rate with inhibition of the renin-angiotensin system does not predict subsequent renal and cardiovascular outcomes. Kidney Int. 2017;91(3):683-90.

133. Pugliese G. Updating the natural history of diabetic nephropathy. Acta Diabetol. 2014;51(6):905-15.

134. Onuigbo MA, Agbasi N. Diabetic nephropathy and CKD-analysis of individual patient serum creatinine trajectories: a forgotten diagnostic methodology for diabetic CKD prognostication and prediction. J Clin Med. 2015:4(7):1348-68

135. Thakar CV, Christianson A, Himmelfarb J, Leonard AC. Acute kidney injury episodes and chronic kidney disease risk in diabetes mellitus. Clin J Am Soc Nephrol. 2011;6(11):2567-72.

136. Ascon M, Ascon DB, Liu M, Cheadle C, Sarkar C, Racusen L, et al. Renal ischemia-reperfusion leads to long term infiltration of activated and effector-memory T lymphocytes. Kidney Int. 2009;75(5):526-35.

137. Basile DP, Anderson MD, Sutton TA. Pathophysiology of acute kidney injury. Compr Physiol. 2012;2(2):1303-53.

138. Basile DP, Donohoe $D$, Roethe K, Osborn JL. Renal ischemic injury results in permanent damage to peritubular capillaries and influences longterm function. Am J Physiol Renal Physiol. 2001;281(5):F887-99.

139. Chawla LS, Kimmel PL. Acute kidney injury and chronic kidney disease: an integrated clinical syndrome. Kidney Int. 2012:82(5):516-24.

140. Redon J. Measurement of microalbuminuria-what the nephrologist should know. Nephrol Dial Transplant. 2006;21 (3):573-6.

141. Levey AS, Stevens LA, Schmid CH, Zhang YL, Castro AR, Feldman HI, et al. A new equation to estimate glomerular filtration rate. Ann Intern Med. 2009;150(9):604-12.
142. Kong X, Ma Y, Chen J, Luo Q, Yu X, Li Y, et al. Evaluation of the chronic kidney disease epidemiology collaboration equation for estimating glomerular filtration rate in the Chinese population. Nephrol Dial Transplant. 2013;28(3):641-51.

143. Classification and diagnosis of diabetes. Diabetes Care. 2016;39 Suppl 1:S13-22.

\section{Publisher's Note}

Springer Nature remains neutral with regard to jurisdictional claims in published maps and institutional affiliations.
Ready to submit your research? Choose BMC and benefit from:

- fast, convenient online submission

- thorough peer review by experienced researchers in your field

- rapid publication on acceptance

- support for research data, including large and complex data types

- gold Open Access which fosters wider collaboration and increased citations

- maximum visibility for your research: over 100M website views per year

At BMC, research is always in progress.

Learn more biomedcentral.com/submissions 